Research Article

\title{
Effect of the Drum Height on the Seismic Behaviour of a Free-Standing Multidrum Column
}

\author{
Ante Buzov (i), Jure Radnić, Nikola Grgić ${ }^{D}$, and Goran Baloević \\ Faculty of Civil Engineering, Architecture and Geodesy, University of Split, 21000 Split, Croatia \\ Correspondence should be addressed to Ante Buzov; ante.buzov@gradst.hr
}

Received 8 March 2018; Accepted 24 May 2018; Published 19 June 2018

Academic Editor: Andrey E. Miroshnichenko

Copyright (C) 2018 Ante Buzov et al. This is an open access article distributed under the Creative Commons Attribution License, which permits unrestricted use, distribution, and reproduction in any medium, provided the original work is properly cited.

\begin{abstract}
The results of a shake-table study on the effect of the drum height on the seismic behaviour and bearing capacity of small-scale free-standing multidrum columns are presented. Columns of equal height with one, three, and six drums through their height were considered for the case of their self-weight only and for the case with an additional weight on the top of the column. The columns were exposed to a horizontal base acceleration of three accelerograms by successively increasing the maximum acceleration to their failure. The characteristic displacements and accelerations of the column were measured. It was concluded that an increase in the number of blocks in the column can significantly increase or decrease its ultimate bearing capacity, depending on the type of the applied accelerogram. It is expected that the experimental database can be useful in the validation of nonlinear numerical models for the dynamic analysis of multidrum columns.
\end{abstract}

\section{Introduction}

Multidrum stone columns are important structural elements of historic buildings. Their behaviour during an earthquake depends on numerous parameters, such as the number of blocks, boundary conditions at the top and bottom of the column, the type and processing of joints, the level of gravitational stresses, stone quality, interaction with possible walls, slenderness, precision of construction, foundation deformability, local effects, and earthquake type.

Because of the great importance of historical buildings, the studies regarding the seismic behaviour of stone structures, especially multidrum stone columns, are still up to date.

Unfortunately, only a small number of numerical and especially experimental investigations of multidrum stone columns under an earthquake have been conducted to date. In doing so, only some parameters that affect their seismic response and bearing capacity have been investigated. Several of these studies are briefly listed below.

Contemporary numerical studies on the seismic behaviour of multidrum columns are mainly based on the discrete element method. Using this method, Sarhosis et al. [1] analysed the colonnade of the Forum in Pompeii; Papaloizou and Komodromos [2] analysed multidrum ancient columns and colonnades; Komodromos et al. [3] investigated ancient columns; Konstantinidis and Makris [4] considered a multidrum classical column; Psycharis et al. [5] analysed part of the Parthenon Pronaos; Papantonopoulos et al. [6] analysed classical columns; Sarhosis et al. [7] performed threedimensional modelling of ancient colonnade structural systems subjected to harmonic and seismic loading; and Asteris et al. [8] analysed historic masonry structures.

Contemporary experimental studies regarding the seismic behaviour of multidrum columns are based on shake-table testing. Thus, Drosos and Anastasopoulos [9] studied a free-standing reduced-scale multidrum column; Drosos and Anastasopoulos [10] investigated an ancient Greek temple; Mouzakis et al. [11] analysed a marble model of a classical column; and Krstevska et al. [12] analysed a model of the Antonina column in Rome. The abovementioned numerical and experimental studies have not been described more closely because they are not considered in this article.

This paper presents the experimental study results regarding the effect of the number of blocks in a multidrum 


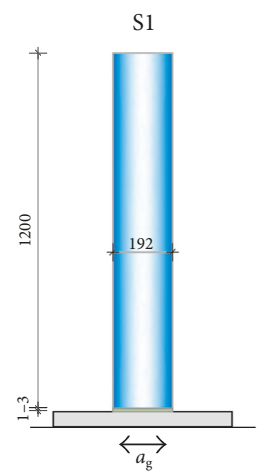

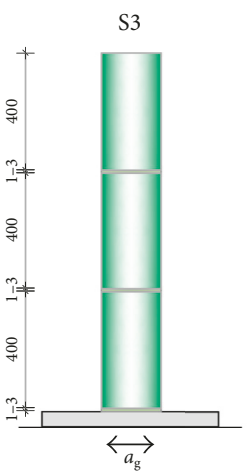

(a)
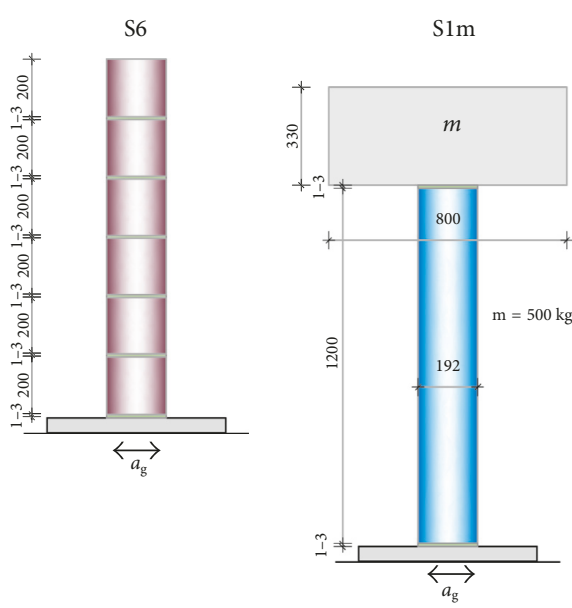

$\mathrm{S} 3 \mathrm{~m}$

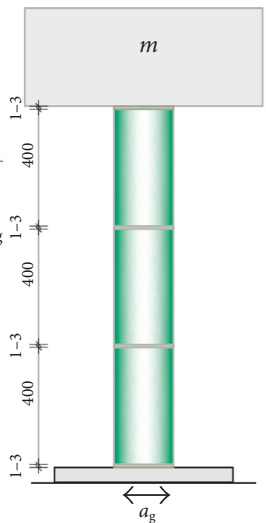

(b)

Figure 1: Tested free-standing columns: (a) self-weight only and (b) self-weight and mass at the top.

column on its seismic behaviour. The behaviour of smallscale free-standing multidrum columns without and with the mass at the top was studied by shake-table testing. The columns were exposed to the horizontal base acceleration of three different accelerograms. Columns made from one, three, and six blocks per their height with stone powder joints were considered. In addition to the new insights of the effect of the drum height on the seismic behaviour of multidrum columns, one of the aims of this study was to create an experimental database for the possible validation of nonlinear numerical models for the seismic analysis of such columns. The main conclusions of the study are given at the end of the article. According to the authors' knowledge, such research has not been performed to date. It is believed that the given conclusions can be applied to multidrum columns in practice.

Summarized findings of the study are as follows:

(i) An important effect of the number of blocks in the multidrum column on its seismic response was investigated, which has not been investigated yet.

(ii) A reliable experimental approach to research considered problem with the shake-table has been adopted, which can be easily repeated.

(iii) Column models were tested to the failure on different earthquake types, with and without mass at their top.

(iv) The results of the research are applicable in practice.

(v) Generated experimental database can be useful in verifying numerical models for seismic analysis of multidrum columns.

1.1. Tested Columns. The small-scale free-standing multidrum columns (Figure 1) with approximately equal height formed from one, three, and six blocks per column height were tested. The columns S1, S3, and S6 (Figure 1(a)) were loaded only by self-weight, and the identical columns $\mathrm{S} 1 \mathrm{~m}$, S2m, and S6m (Figure 1(b)) were loaded with additional
TABLe 1: Fundamental free oscillation period $T_{1}$ of the tested columns.

\begin{tabular}{ccccccc}
\hline & S1 & S3 & S6 & S1m & S3m & S6m \\
\hline$T_{1}(\mathrm{~s})$ & 0.054 & 0.072 & 0.152 & 0.179 & 0.232 & 0.507 \\
\hline
\end{tabular}

weight at their top. The columns have a circular cross section with a $192 \mathrm{~mm}$ diameter. These columns were supported on a shake table indirectly over a $50 \mathrm{~mm}$ thick, rigid concrete plate fixed to the shake table. Thin joints $(1-3 \mathrm{~mm})$ from stone powder were formed between the blocks, between the block and the bottom plate, and between the block at the top of the column and mass $(m)$. Such joints were used to reduce the stress concentration in the nonideal flat dry joint, that is, to ensure an equal adjustment of the contact surfaces between the blocks and an equal transmission of vertical and horizontal stresses in the joint, as well as to simplify the column construction. The type of the joint also affects the behaviour of the multidrum columns. This issue was investigated by Buzov et al. [13] for static loads. The height of the columns was approximately $1200 \mathrm{~mm}$, and their slenderness 1 was approximately 35 . The mass at the top of the column $(m=500 \mathrm{~kg})$, which is centrally positioned in relation to its axis, was formed from a rigid concrete block with dimensions of $0.8 \times 0.8 \times 0.33 \mathrm{~m}$.

The columns S1 and S1m were formed from one $1200 \mathrm{~mm}$ high block, the columns S3 and S3m from three $400 \mathrm{~mm}$ high blocks, and the columns S6 and S6m from six $200 \mathrm{~mm}$ high blocks. The blocks were made of concrete with a compressive strength of $53.55 \mathrm{MPa}$, obtained on the cylinder according to [14]. Although the subject of this study is stone columns, concrete blocks were used instead of stone blocks for several reasons $[13,15]$ : (i) unreliability of the uniformity of the stone quality (the probable presence of anomalies in the stone), (ii) great similarity of stone and concrete properties (artificial stone), (iii) low level of maximum stress in the blocks (the collapse of a column is due to the loss of its stability), and (iv) lower research costs. This approach did not greatly influence the given conclusions of this study. 


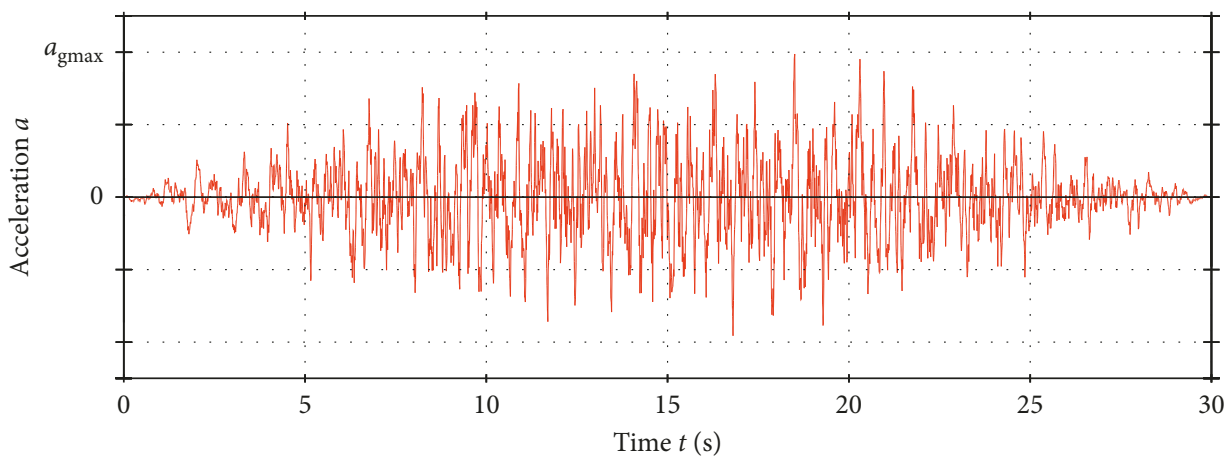

(a)

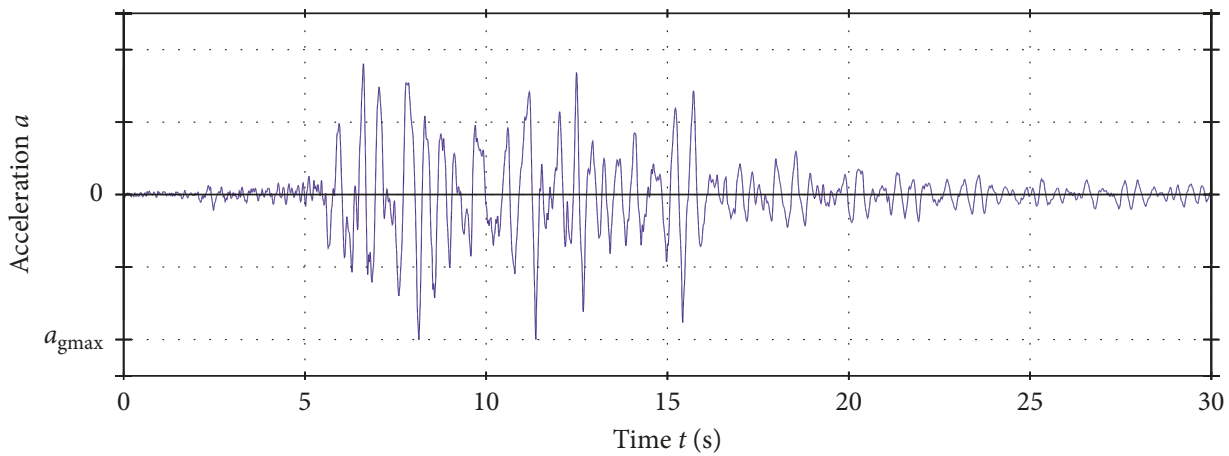

(b)

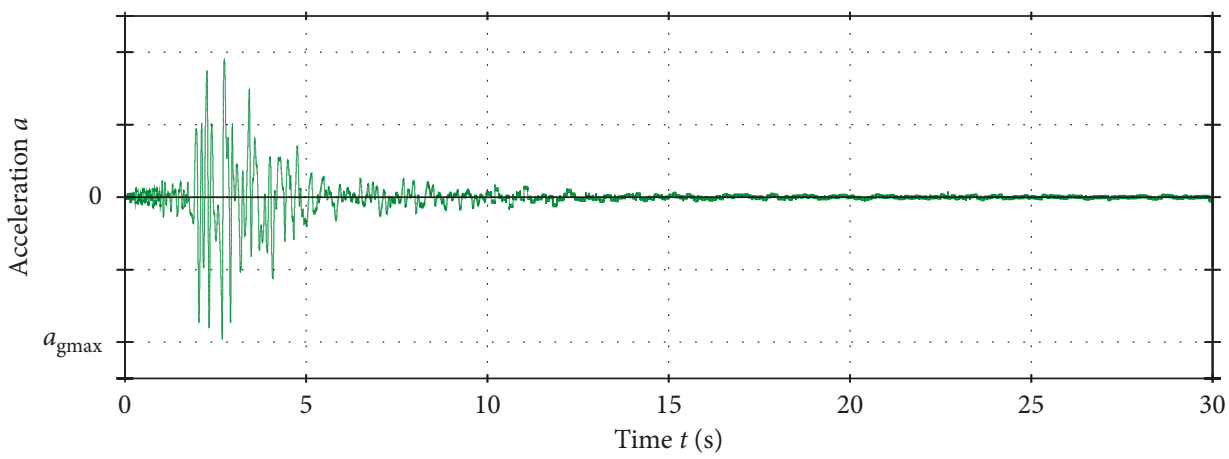

(c)

FIgURE 2: Applied horizontal base accelerations: (a) artificial accelerogram; (b) Petrovac accelerogram; (c) Ston accelerogram.

The experimentally determined first free oscillation period $T_{1}$ of the considered columns is shown in Table 1. The significant effect of the number of blocks in the column and the mass at the column top on $T_{1}$ is evident. By increasing the number of blocks, $T_{1}$ increases, that is, the column stiffness decreases. The mass at the top of the column also increases $T_{1}$. The relation of the basic period for the columns S1, S3, and S6 is $1: 1.33: 2.82$, and the relation for the columns $\mathrm{S} 1 \mathrm{~m}, \mathrm{~S} 3 \mathrm{~m}$, and $\mathrm{S} 6 \mathrm{~m}$ is $1: 1.30: 2.8$.

1.2. Applied Accelerograms. The tested columns from Figure 1 were subjected to a horizontal base acceleration of the three accelerograms according to Figure 2: (i) the artificial accelerogram (Figure 2(a)) generated from the elastic response spectrum in accordance with [16] for type 1 and soil type A; (ii) the N-S horizontal component of the Petrovac earthquake
[17], Montenegro (Figure 2(b)); and (iii) the N-S horizontal component of the Ston earthquake [17], Croatia (Figure 2(c)). The spectral values of the adopted accelerograms are presented in Figure 3. The artificial and Petrovac accelerograms are characterized by long-lasting action, where the predominant period of the Petrovac accelerogram is somewhat longer. The Ston accelerogram is characterized by a short impact action with a short predominant period. By considering the basic periods of the columns from Table 1 and the spectral values of the applied excitations from Figure 3, it is expected that the artificial and Petrovac accelerograms are more unfavourable than the Ston accelerogram. However, due to the possibility of the occurrence of nonlinearities in the joints (sliding and rotation), it is difficult to predict which accelerogram would be the most unfavourable for each column in Figure 1.

All the accelerograms in Figure 2 were applied with a successive increase in the maximum acceleration $a_{\text {gmax }}$, 


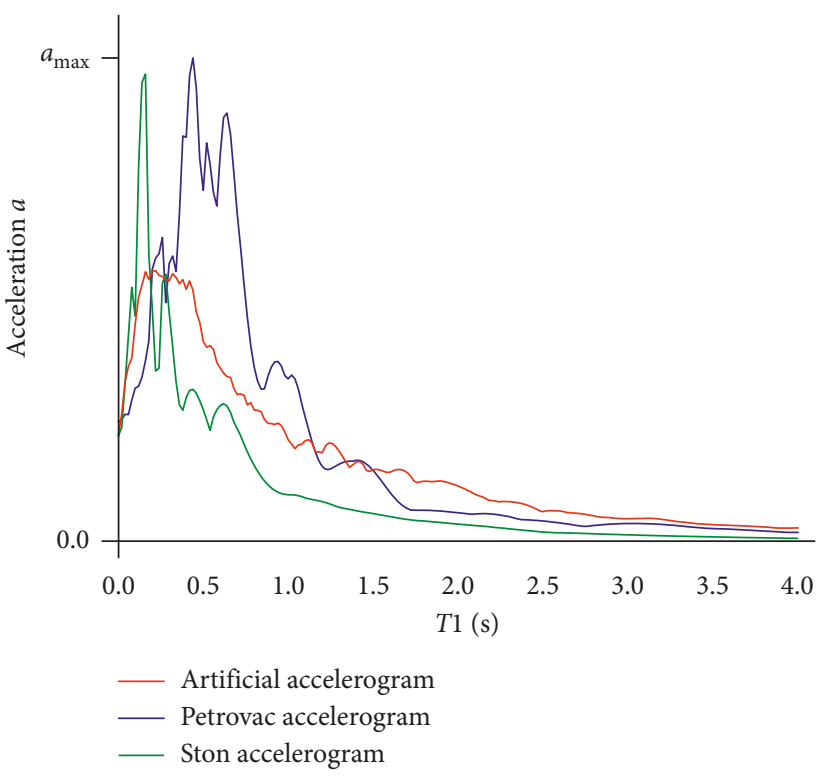

(a)

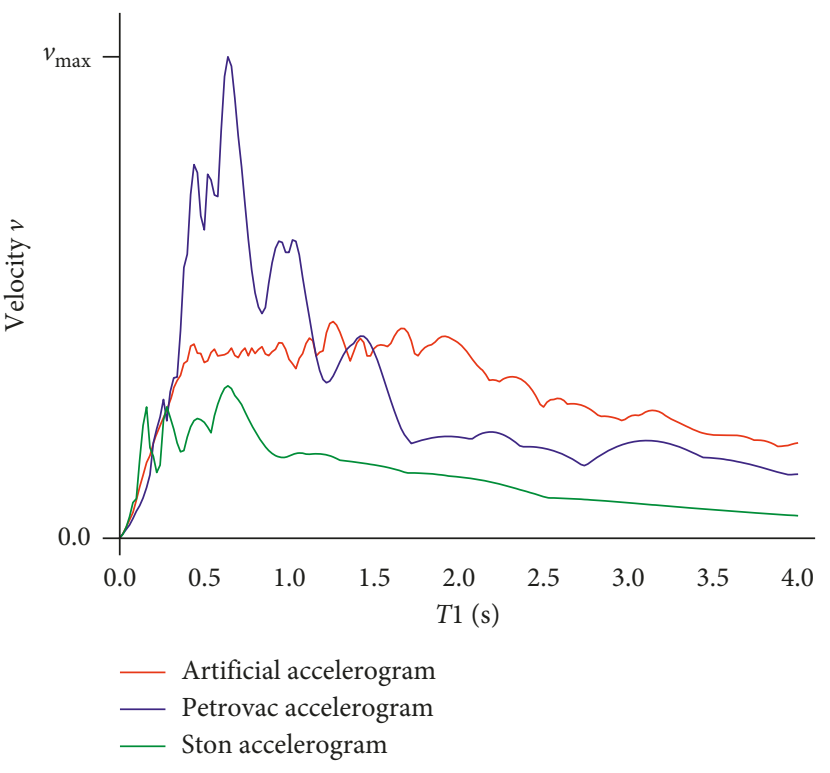

(b)

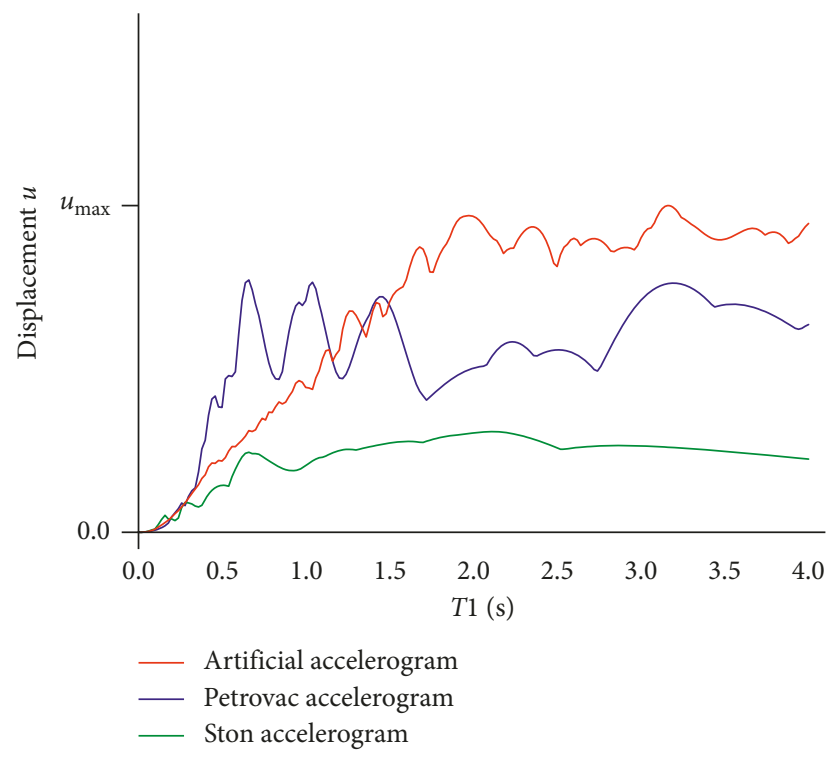

(c)

FIGURE 3: Spectral values for the adopted accelerograms: (a) accelerations; (b) velocities; (c) displacements.

until the collapse of the column. For the artificial accelerogram and the Petrovac accelerogram, the increment in the acceleration $\Delta a_{\text {gmax }}$ was adopted as $0.2 \mathrm{~ms}^{-2}$, and $\Delta a_{\text {gmax }}$ for the Ston accelerogram was employed as $0.5 \mathrm{~ms}^{-2}$. Although only three different base accelerations were adopted to shorten the research, it is believed that this has no practical influence on the given conclusions.

1.3. Measured Quantities and Equipment. The horizontal displacements $u_{i}$ of the top and bottom of the blocks $(5 \mathrm{~mm}$ from their edges) for each tested specimen were measured according to Figure 4, as well as the horizontal acceleration $a_{i}$ in the middle of the drum height. The motion of the columns during base excitation was recorded by a precise video camera.
The shake table at the University of Split, Faculty of Civil Engineering, Architecture and Geodesy, was used. A QuantumX MX840A system (HBM) was used to record the data from the sensors. Analogue displacement sensors PB25-S10-NOS-10C (UniMeasure) were used for the measured displacements, and the accelerations were measured by a type 4610 piezoelectric high-frequency accelerometer (MS).

1.4. Test Results. Before the final tests were performed, the accuracy of the recurrent tests was measured to verify their reliability. Specifically, for the S3 and S3m columns, three identical tests were performed for the artificial and Petrovac accelerograms. The maximum difference in the measured 

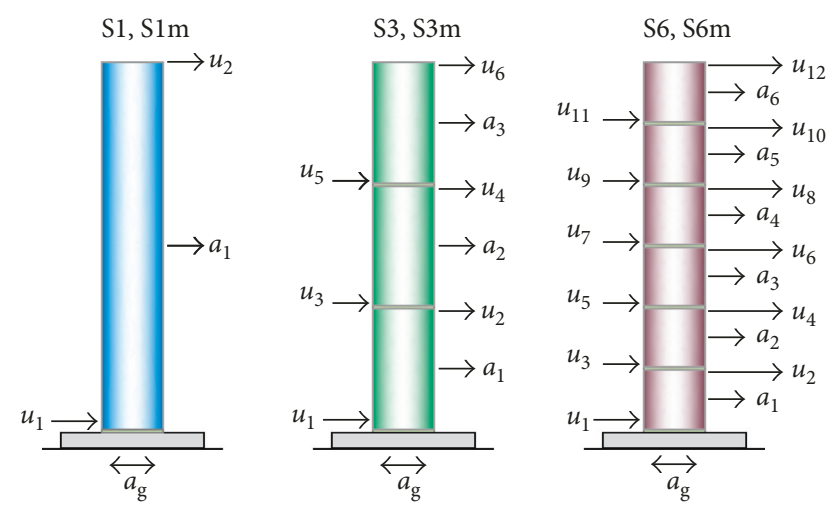

FIgURE 4: Measured quantities.

values for each test was up to $4.8 \%$. Given the sensitivity of the problem and the possible effect of different parameters (column verticality, inhomogeneity in joints, mass eccentricity at the top of the column, precision of the acceleration application by the shake table, imperfections in the measurement equipment and measurements, etc.), it was suggested that these deviations are within acceptable limits and have no practical influence on the given conclusions. Therefore, because of the simple presentation of the measured values, the final tests were conducted on a single specimen.

Only some test results are graphically presented and briefly discussed. The maximum base acceleration $a_{\operatorname{gmax}}$ values for the columns S1, S3, and S6 in their limit state are shown in Figure 5, where the full line indicates $a_{\text {gmax }}$ at the collapse of the columns and a dotted line indicates $a_{\text {gmax }}$ from the previous acceleration increment with the preserved stability of the columns. It is evident that the column bearing capacity depends on the number of blocks in the column and the applied accelerogram. For the artificial accelerogram, by increasing the number of blocks in a column, its ultimate bearing capacity decreases. For the Petrovac and Ston accelerograms, by increasing the number of blocks in a column, its ultimate bearing capacity increases. Increasing the number of blocks in a column, that is, increasing the number of joints in the column, decreases not only its static stiffness but also its dynamic stiffness. Therefore, lower inertial (earthquake) forces are generated, but at the same time, the column also has a lower resistance. The reduction in the bearing capacity of the column by increasing the number of blocks for the artificial accelerogram can be explained by the fact that this excitation introduced a higher energy in the column. Specifically, this accelerogram has higher spectral displacements and velocities for a higher $T_{1}$ (Figure 3.) than those of the Petrovac accelerogram and especially the Ston accelerogram. The maximum bearing capacity for the Ston accelerogram can be explained by the fact that this excitation has a short impact activity and introduces the lowest energy of the earthquake in the columns; that is, it has the lowest spectral velocities and displacements for a higher $T_{1}$.

For the columns $\mathrm{S} 1 \mathrm{~m}, \mathrm{~S} 3 \mathrm{~m}$, and $\mathrm{S} 6 \mathrm{~m}$ with a mass at the top, the maximum base acceleration $a_{\text {gmax }}$ in their limit state

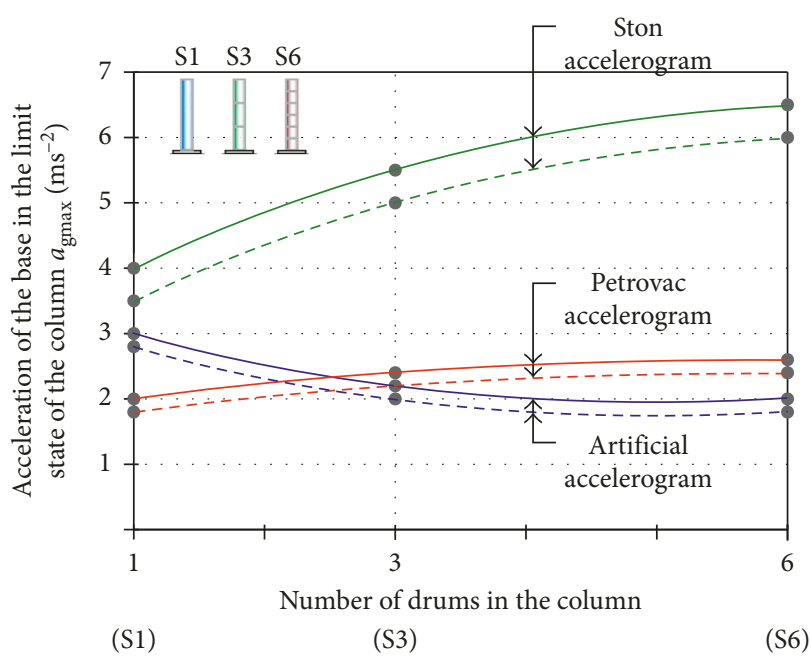

FIgURE 5: Maximum base acceleration $a_{\text {gmax }}$ in the limit state of the columns S1, S3, and S6.

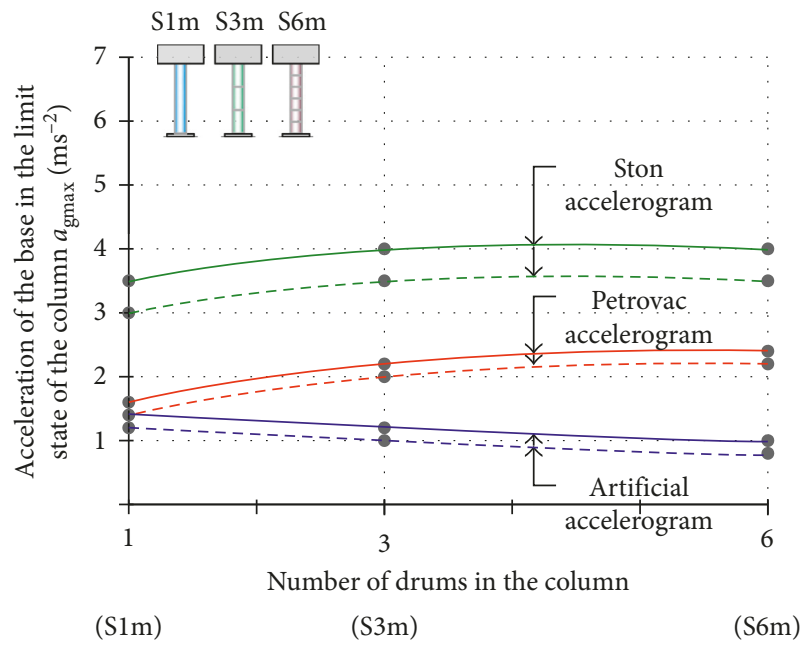

FIgURE 6: Maximum base acceleration $a_{\text {gmax }}$ in the limit state of the columns S1m, S3m, and S6m.

is shown in Figure 6. The full line indicates $a_{\operatorname{gmax}}$ at the failure of the columns, and a dotted line indicates $a_{\text {gmax }}$ from the previous acceleration increment with the preserved stability of the columns. By comparing Figures 5 and 6, a similar behaviour of the columns with a mass at their top and the columns without mass is notable. However, the bearing capacity of the columns $\mathrm{S} 1 \mathrm{~m}, \mathrm{~S} 3 \mathrm{~m}$, and $\mathrm{S} 6 \mathrm{~m}$ is smaller due to the effect of the mass at their top (a significant increase in seismic forces but also an increase in the stability of the column). The similarity of the columns' behaviour for a particular accelerogram is also noticeable. Namely, for the artificial accelerogram, the bearing capacity of the column was also reduced with an increase in the number of blocks, while for the Petrovac and Ston accelerograms, an increase in the number of blocks increased the column's bearing capacity. The explanations are analogous to those for the columns S1, S3, and S6. 

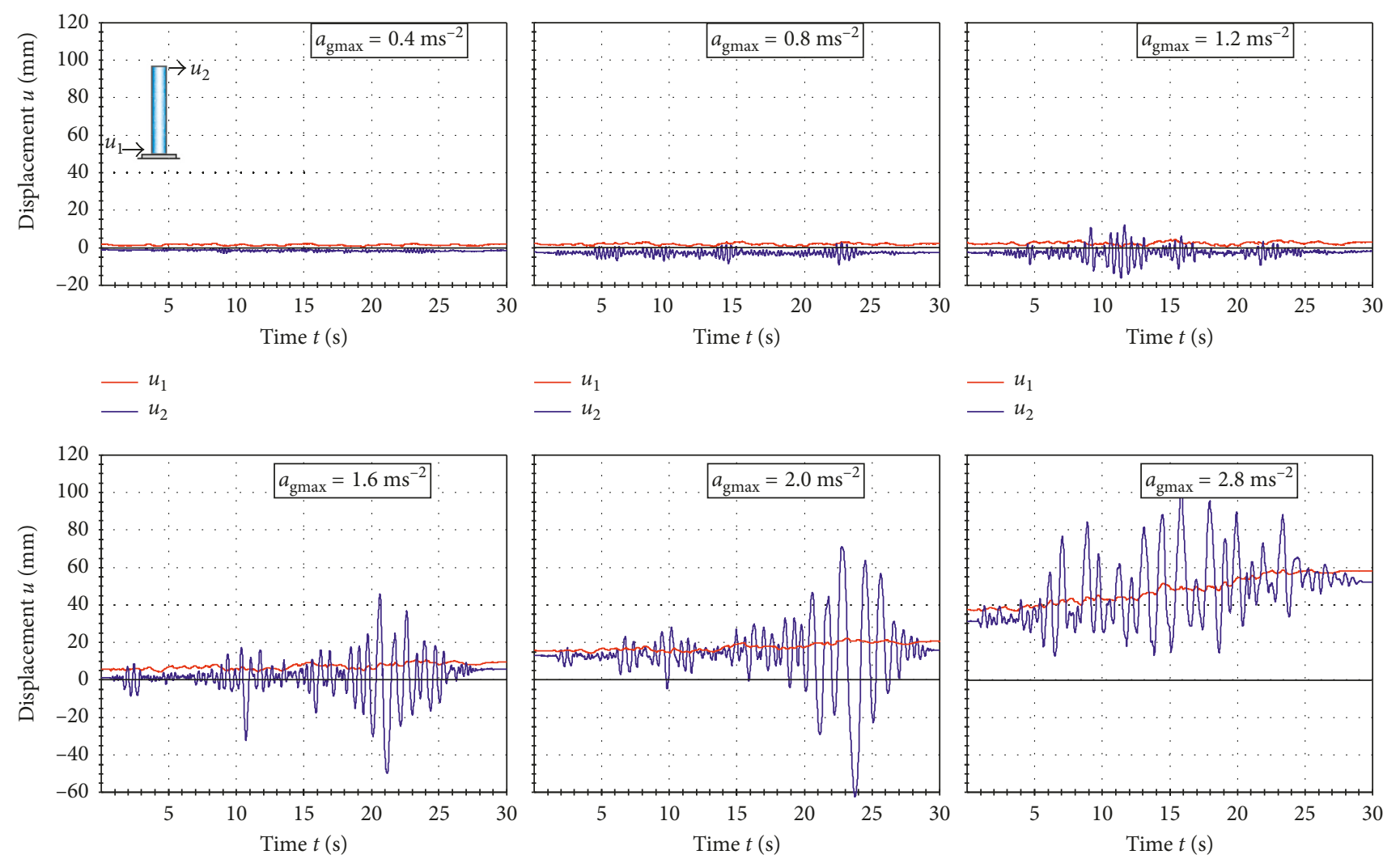

$$
u_{1}
$$$$
\begin{array}{r}
u_{1} \\
-u_{2}
\end{array}-u_{1}
$$

FIgURE 7: Horizontal displacements $u_{1}$ and $u_{2}$ of the column S1 for the artificial accelerogram at some $a_{\text {gmax }}$.
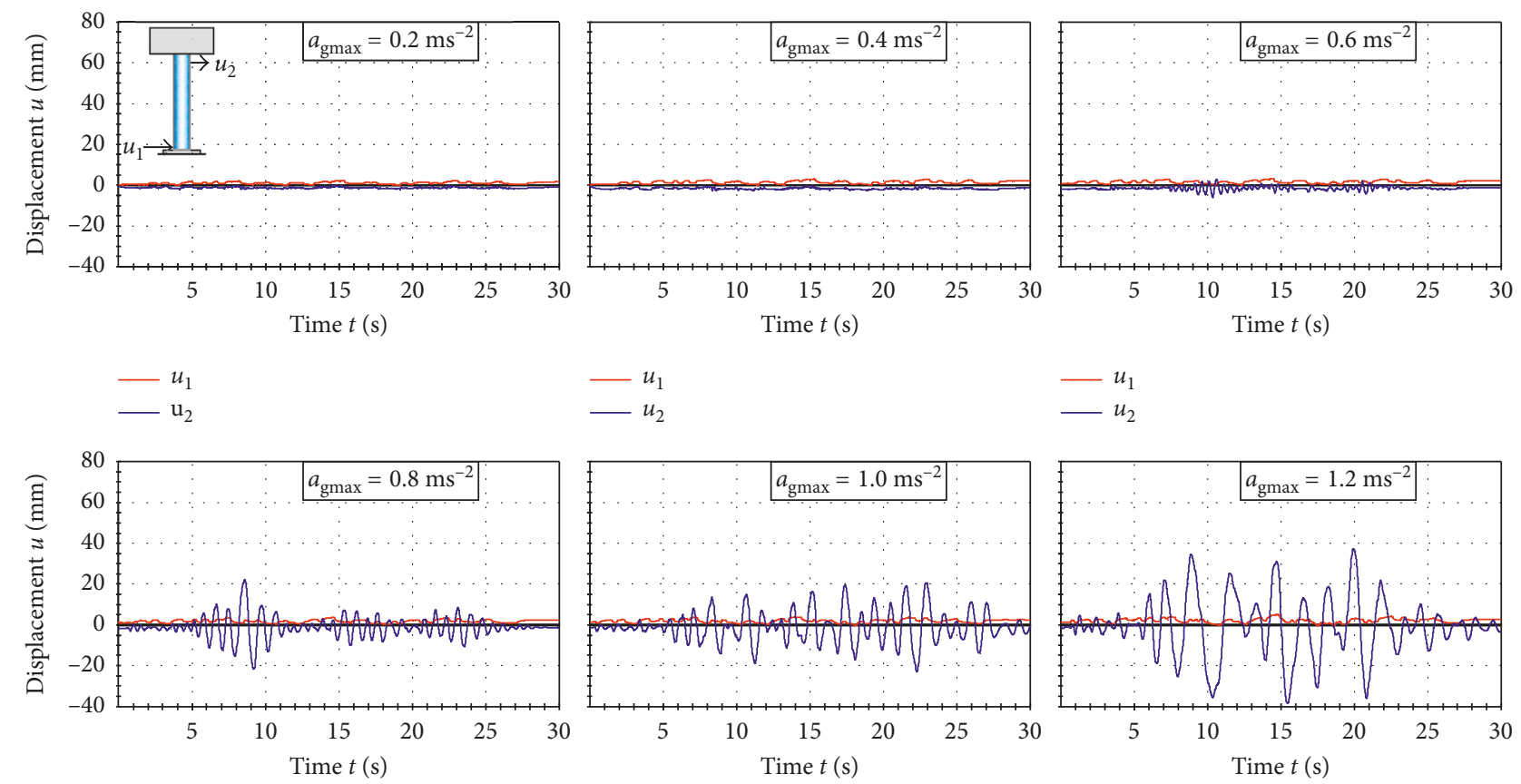

$$
-u_{1}
$$$$
-u_{1}
$$$$
u_{1}-u_{2}
$$

Figure 8: Horizontal displacements $u_{1}$ and $u_{2}$ of the column S1m for the artificial accelerogram at some $a_{\text {gmax }}$. 

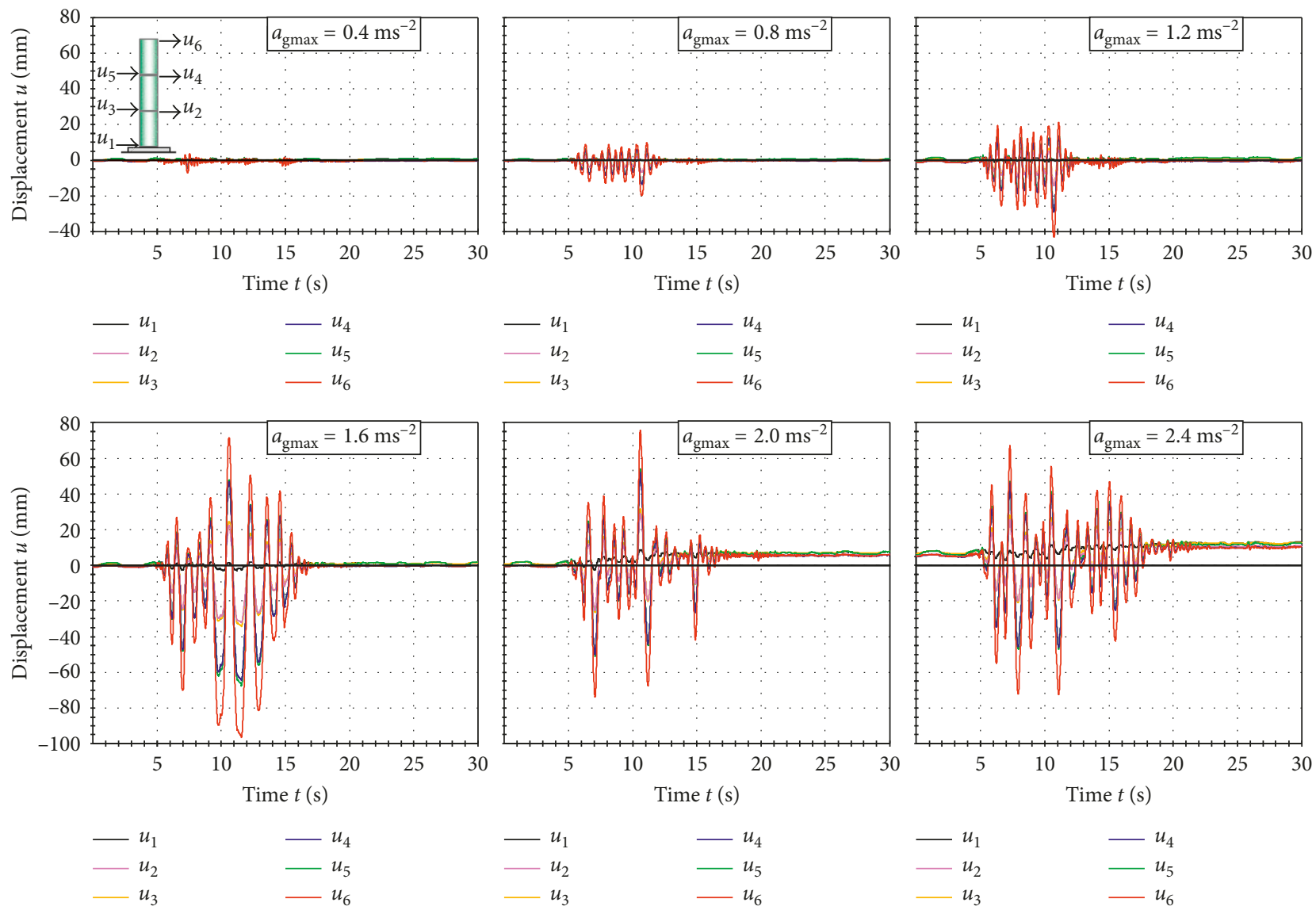

$-u_{1}$
$-u_{2}$
$-u_{3}$

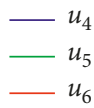

Figure 9: Horizontal displacements $u_{1}$ to $u_{6}$ of the column S3 for the Petrovac accelerogram at some $a_{\text {gmax }}$.
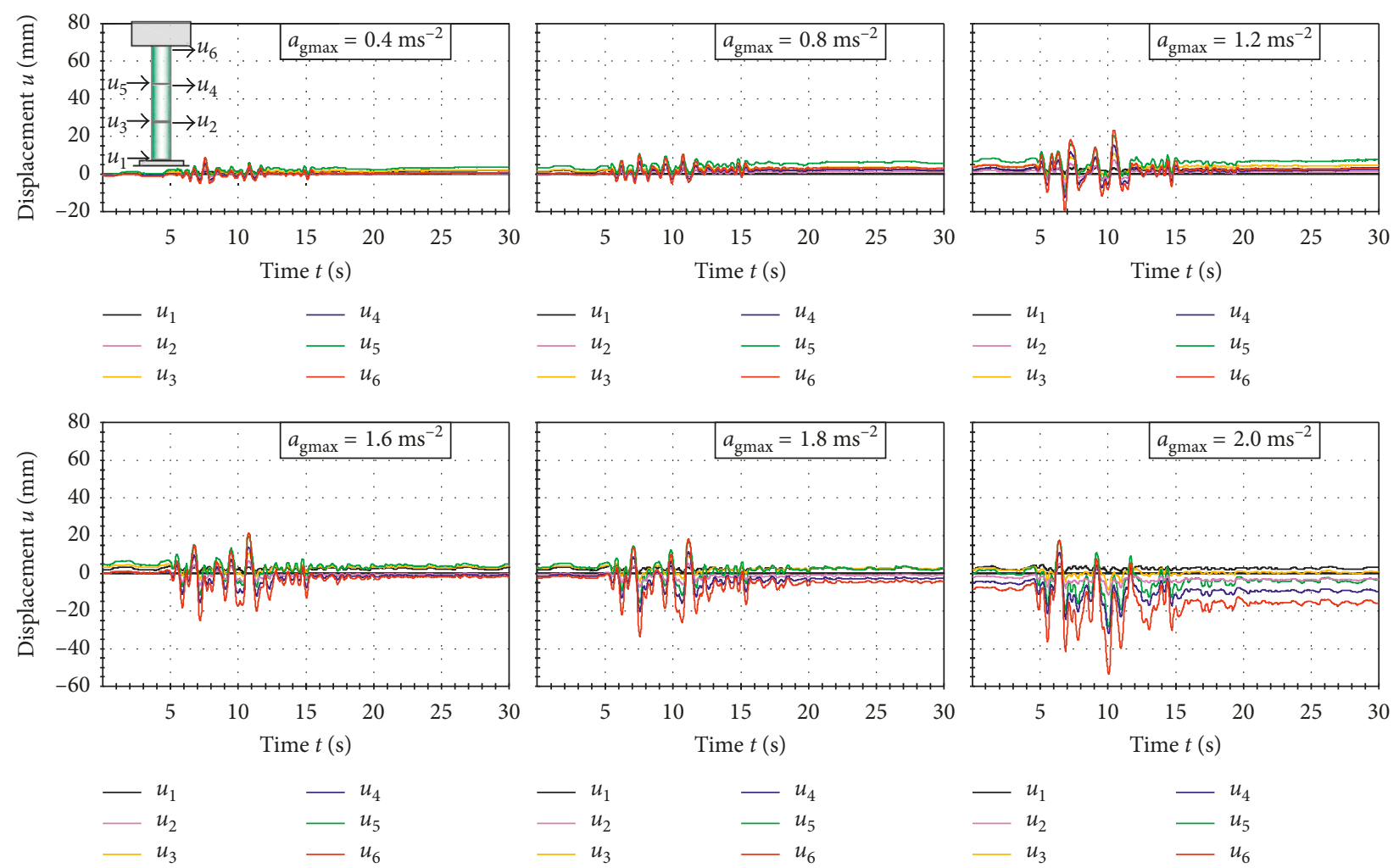

Figure 10: Horizontal displacements $u_{1}$ to $u_{6}$ of the column S3m for the Petrovac accelerogram at some $a_{\text {gmax }}$. 

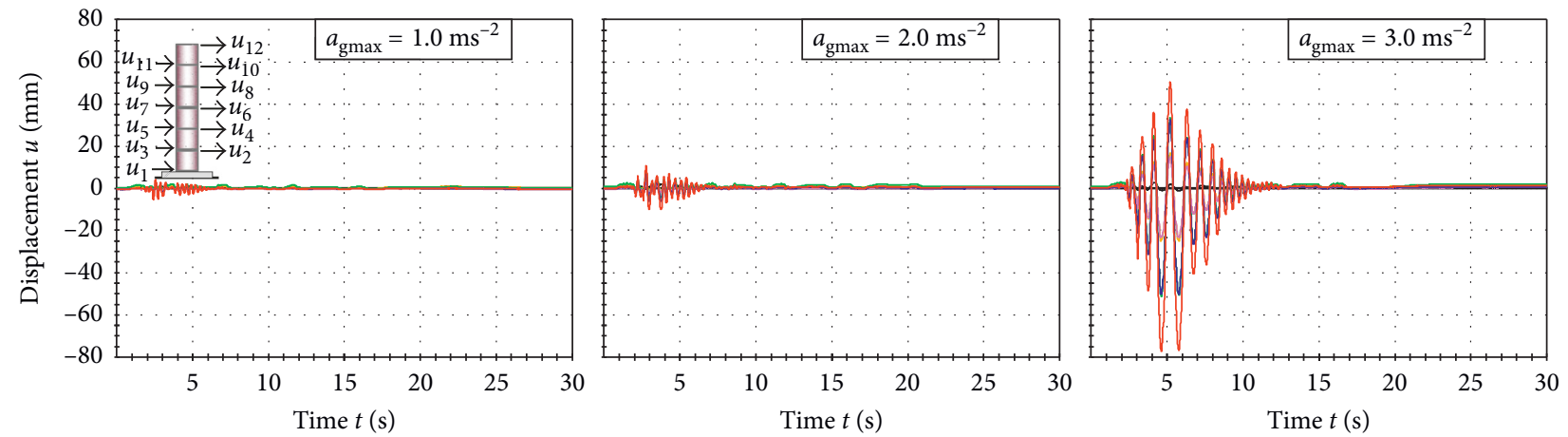
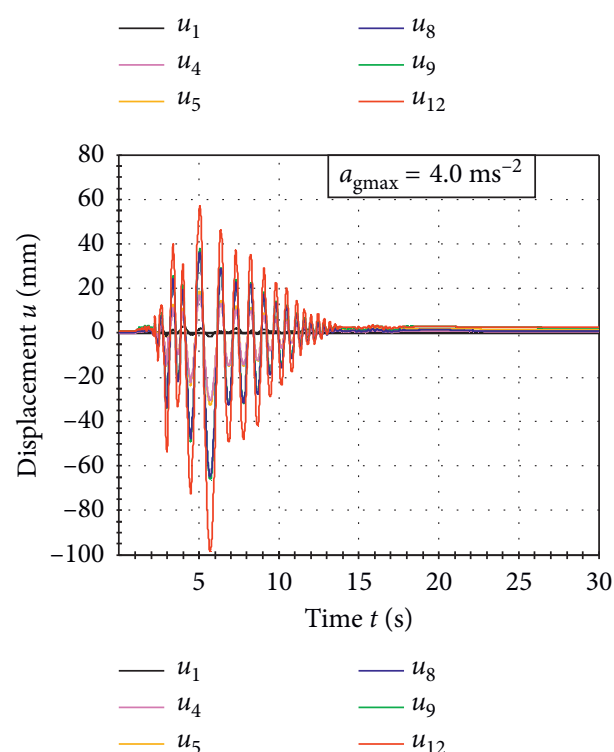
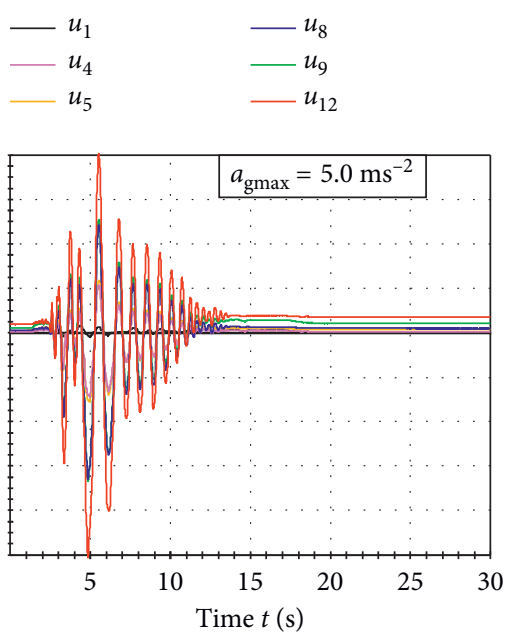

$$
\begin{aligned}
& -u_{8} \\
& -u_{9} \\
& -u_{12}
\end{aligned}
$$

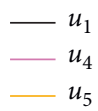

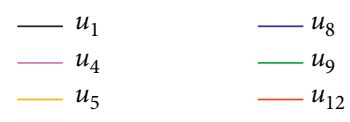
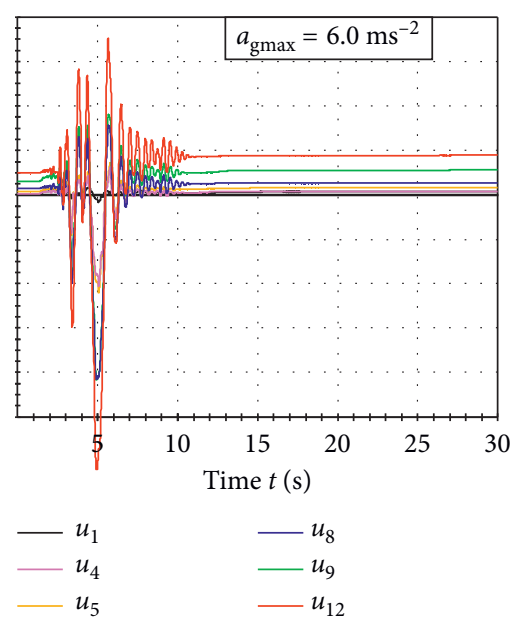

FIgURE 11: Horizontal displacements $u_{1}, u_{4}, u_{5}, u_{8}, u_{9}$, and $u_{12}$ of the column S6 for the Ston accelerogram at some $a_{\text {gmax }}$

The horizontal displacements $u_{1}$ and $u_{2}$ of the column S1 for the artificial accelerogram for some $a_{\text {gmax }}$ are shown in Figure 7 . It is evident that there were no major displacements in the column up to approximately $a_{\mathrm{gmax}}=1.6 \mathrm{~ms}^{-2}$. By increasing $a_{\text {gmax }}$, there was ever-increasing reversible and irreversible displacements of the column. At $a_{\mathrm{g} \max }=2.8 \mathrm{~ms}^{-2}$ (excitation before the column's collapse), the irreversible horizontal displacement of the column's bottom was approximately $60 \mathrm{~mm}$ and that of the column's top was approximately $50 \mathrm{~mm}$ (the column remained in an inclined position). The largest relative displacement of the column's top in relation to its bottom for $a_{\text {gmax }}=2.0 \mathrm{~ms}^{-2}$ was approximately $80 \mathrm{~mm}$.

Figure 8 shows the horizontal displacements $u_{1}$ and $u_{2}$ of the column S1m for the artificial accelerogram for several $a_{\text {gmax }}$. At approximately $a_{\text {gmax }}=0.6 \mathrm{~ms}^{-2}$, the column did not demonstrate large displacements. For the larger $a_{\text {gmax }}$ values, the column's top displacements were significantly increased. At $a_{\mathrm{gmax}}=1.2 \mathrm{~ms}^{-2}$, there were small irreversible displacements of the column's top and bottom. The largest relative displacement of the column's top in relation to its bottom was approximately $40 \mathrm{~mm}$.

The horizontal displacements of the column S3 for the Petrovac accelerogram for some $a_{\text {gmax }}$ are shown in Figure 9. The column's displacements were small at approximately $a_{\text {gmax }}=1.2 \mathrm{~ms}^{-2}$. The maximum displacement of the column's top for $a_{\text {gmax }}=1.6 \mathrm{~ms}^{-2}$ (approximately $100 \mathrm{~mm}$ ) was larger than that for $a_{\mathrm{gmax}}=2.4 \mathrm{~ms}^{-2}$ (approximately $70 \mathrm{~mm}$ ). After the strongest excitation for which the column remained in balance $\left(a_{\mathrm{gmax}}=2.4 \mathrm{~ms}^{-2}\right)$, there were almost equal permanent displacements of all column blocks (approximately $10 \mathrm{~mm}$ ), that is, the column remained almost vertical.

Figure 10 presents the horizontal displacements of the column S3m for the Petrovac accelerogram for some $a_{\text {gmax }}$. The large permanent displacements occurred already at $a_{\text {gmax }}=0.4 \mathrm{~ms}^{-2}$. During the excitation before the column's failure $\left(a_{\text {gmax }}=2.0 \mathrm{~ms}^{-2}\right)$, the permanent displacement of the column's top was approximately $18 \mathrm{~mm}$. Thus, the column's bottom remained in the initial position before testing.

Some horizontal displacements of the column S6 for the Ston accelerogram for some $a_{\text {gmax }}$ are shown in Figure 11. The other displacements are not presented for the clear presentation of drawings. The column demonstrated large reversible displacements already at $a_{\mathrm{gmax}}=3.0 \mathrm{~ms}^{-2}$ but practically without any permanent displacements. At $a_{\text {gmax }}=6.0 \mathrm{~ms}^{-2}$, the top of the column had a large permanent displacement of approximately $120 \mathrm{~mm}$, and the tallest block exhibited large permanent displacements.

Figure 12 presents several horizontal displacements of the column $56 \mathrm{~m}$ for the Ston accelerogram at some $a_{\text {gmax }}$. The permanent displacements of the column occurred 

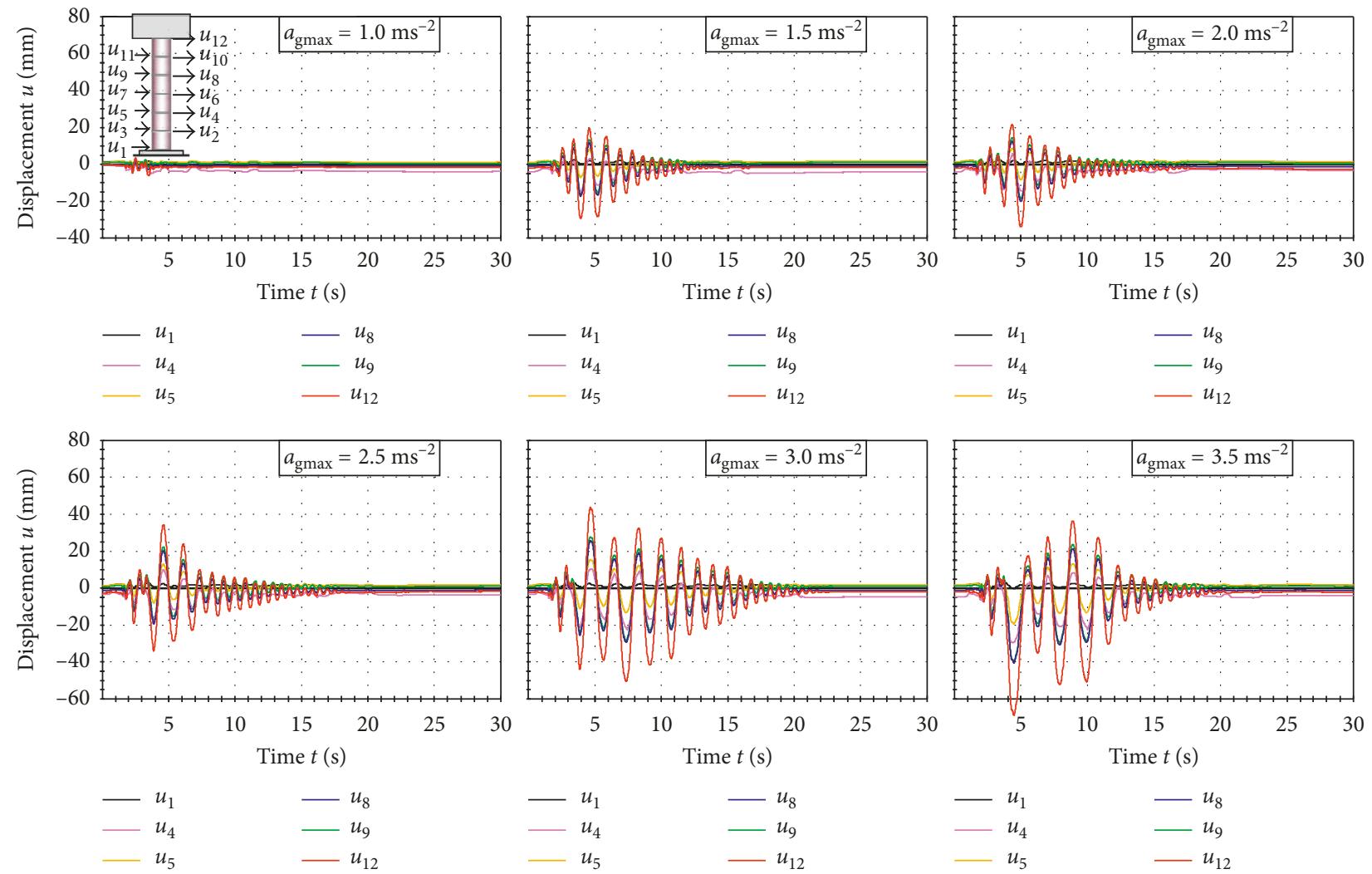

$\begin{array}{ll}-u_{1} & -u_{8} \\ -u_{4} & -u_{9} \\ -u_{5} & -u_{12}\end{array}$

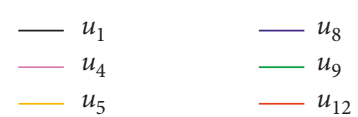

FIGURE 12: Horizontal displacements $u_{1}, u_{4}, u_{5}, u_{8}, u_{9}$, and $u_{12}$ of the column S6m for the Ston accelerogram at some $a_{\text {gmax }}$.

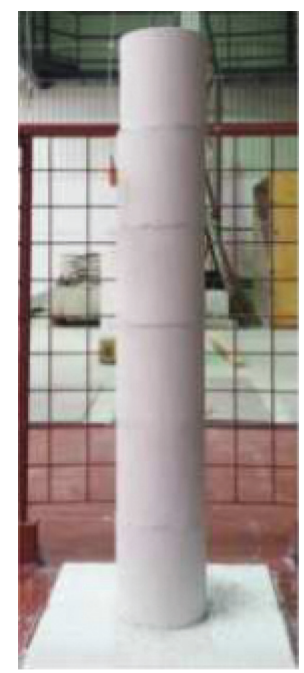

(a)

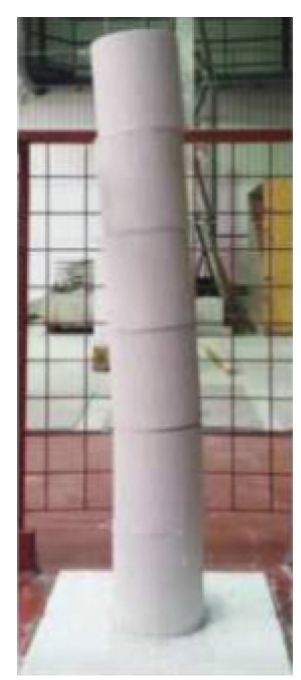

(b)

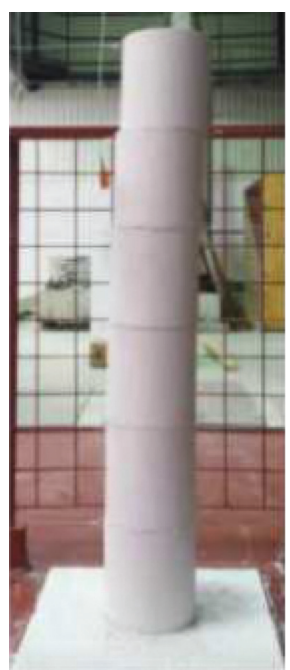

(c)

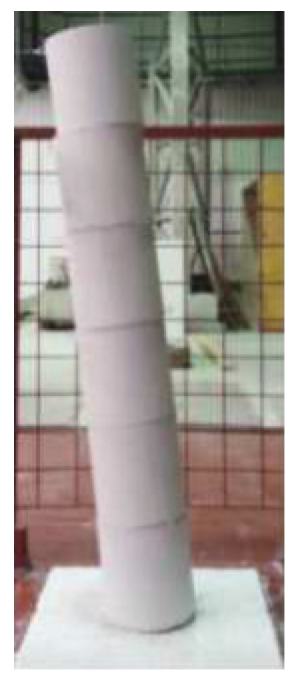

(d)

Figure 13: Continued. 


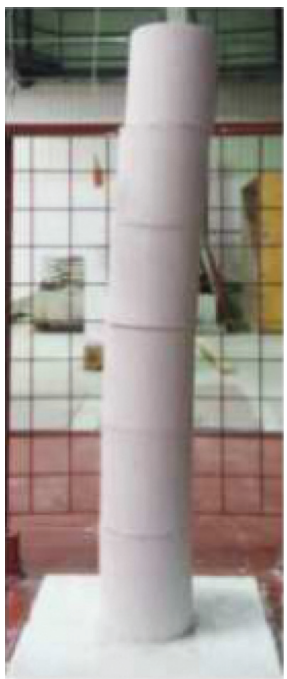

(e)

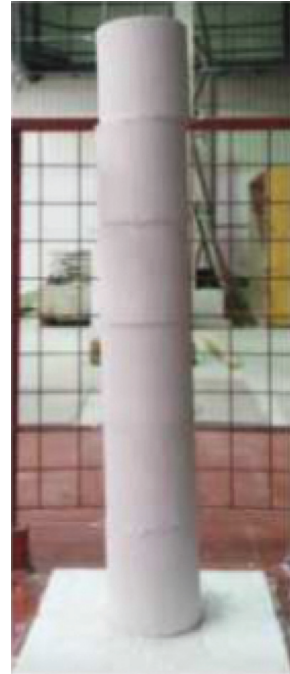

(f)

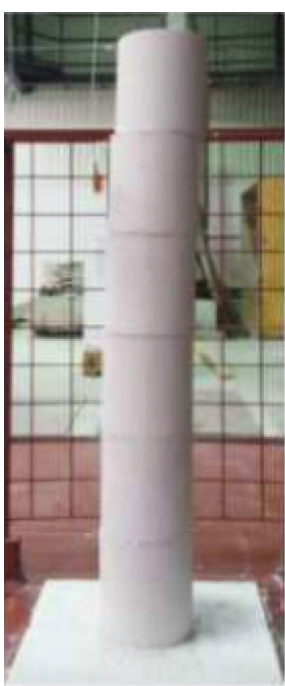

(g)

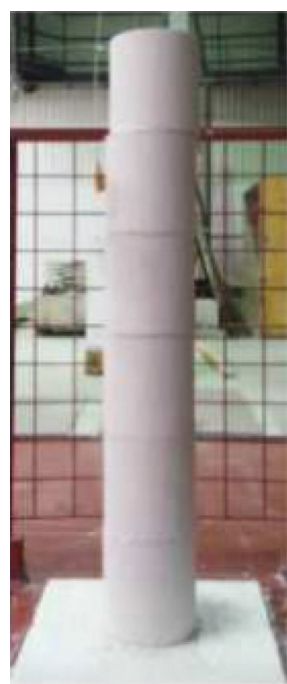

(h)

FIGURE 13: Appearance of the column S6 for the Ston accelerogram at $a_{\text {gmax }}=6.0 \mathrm{~ms}^{-2}$ at different periods of time: (a) $t=2.8 \mathrm{~s}$, (b) $t=3.4 \mathrm{~s}$, (c) $t=3.8 \mathrm{~s}$, (d) $t=4.9 \mathrm{~s}$, (e) $t=5.6 \mathrm{~s}$, (f) $t=6.1 \mathrm{~s}$, (g) $t=6.4 \mathrm{~s}$, and (h) $t=6.7 \mathrm{~s}$.

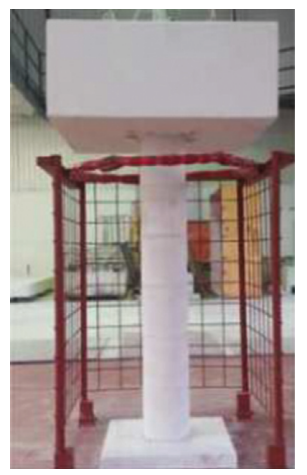

(a)

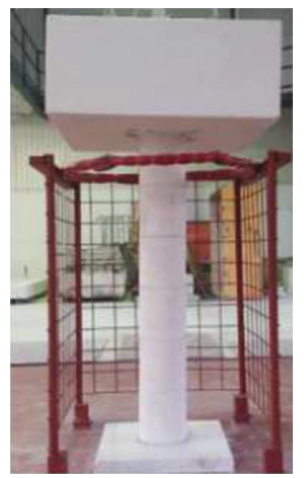

(e)

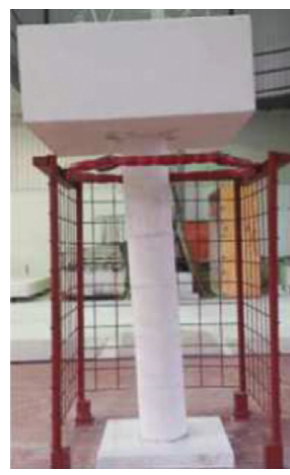

(b)

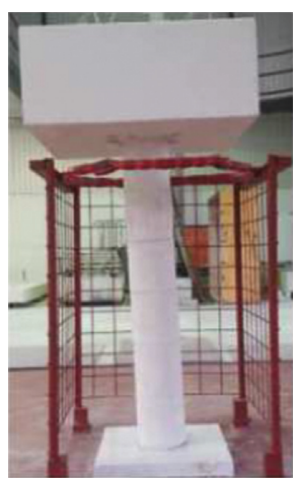

(f)

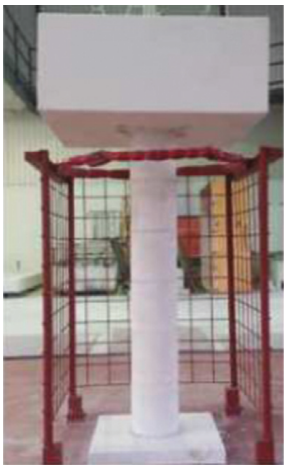

(c)

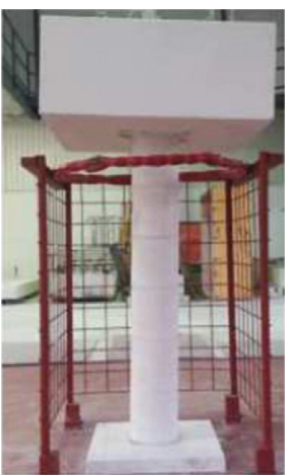

(g)

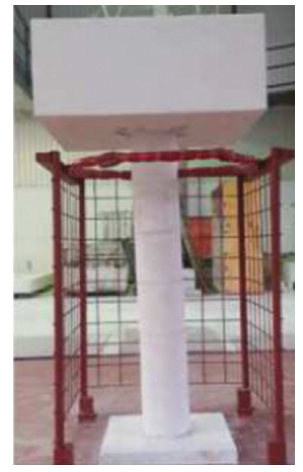

(d)

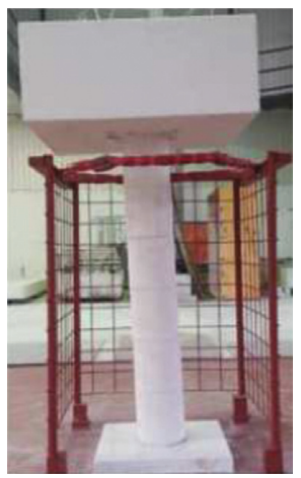

(h)

FIGURE 14: Appearance of the column S6m for the Ston accelerogram at $a_{\text {gmax }}=3.5 \mathrm{~ms}^{-2}$ at different periods of time: (a) $t=2.4 \mathrm{~s}$, (b) $t=4.5 \mathrm{~s}$, (c) $t=5.5 \mathrm{~s}$, (d) $t=6.2 \mathrm{~s}$, (e) $t=7.0 \mathrm{~s}$, (f) $t=7.9 \mathrm{~s}$, (g) $t=8.9 \mathrm{~s}$, and (h) $t=9.9 \mathrm{~s}$.

already at $a_{\text {gmax }}=1.0 \mathrm{~ms}^{-2}$, which did not significantly increase in the following stronger excitation. The largest displacement of the column's top at $a_{\text {gmax }}=3.5 \mathrm{~ms}^{-2}$ was approximately $70 \mathrm{~mm}$.
Some photographs of the column S6 for the Ston accelerogram at $a_{\text {gmax }}=6.0 \mathrm{~ms}^{-2}$ at a certain time according to Figure 11 are shown in Figure 13, and several photographs of the column S6m for the same excitations at $a_{\mathrm{gmax}}=3.5 \mathrm{~ms}^{-2}$ at 
a certain time in accordance with Figure 12 are shown in Figure 14. Notably, the relative displacements between the blocks were smaller for the column $56 \mathrm{~m}$ than for the column S6.

\section{Conclusions}

Based on the results of the performed shake-table study on the behaviour and ultimate bearing capacity of the freestanding small-scale multidrum columns (S1, S3, and S6; $\mathrm{S} 1 \mathrm{~m}, \mathrm{~S} 3 \mathrm{~m}$, and $\mathrm{S} 6 \mathrm{~m}$ ) formed from one, three, and six blocks through their height with stone powder joints with variations in the columns gravity load (S1, S3, and S6: only selfweight; S1m, S3m, and S6m: self-weight and $500 \mathrm{~kg}$ mass at the top) and three different successively increased horizontal base accelerations (artificial, Petrovac, and Ston accelerograms), the main conclusions given below can be drawn.

The number of blocks in the multidrum column significantly affects its stiffness, resistance, and bearing capacity under an earthquake load.

The columns loaded with self-weight only (S1, S3, and S6) and the identical columns with a mass at their top (S1m, $\mathrm{S} 3 \mathrm{~m}$, and $\mathrm{S6m}$ ) had a similar effect to the number of blocks on their bearing capacity. However, the columns with the mass at their top had a lower bearing capacity because of additional seismic (inertial) forces caused by the mass.

The effect of the number of blocks in the column on its bearing capacity was dependent on the applied accelerogram (earthquake type). For an artificial accelerogram, the column's bearing capacity was reduced with the increase in the number of blocks in the column. The ratios of bearing capacity of the columns were approximately $\mathrm{S} 1: \mathrm{S} 3: \mathrm{S} 6=1: 0.71: 0.64$ and $\mathrm{S} 1 \mathrm{~m}: \mathrm{S} 3 \mathrm{~m}: \mathrm{S} 6 \mathrm{~m}=1: 0.83: 0.66$. For the Petrovac and Ston accelerograms, by increasing the number of blocks in the column, the column's bearing capacity was increased. The ratios of the bearing capacity for the Petrovac accelerogram were $\mathrm{S} 1: \mathrm{S} 3: \mathrm{S} 6=1: 1.22: 1.33$ and $\mathrm{S} 1 \mathrm{~m}: \mathrm{S} 3 \mathrm{~m}: \mathrm{S} 6 \mathrm{~m}=1$ : $1.42: 1.57$. The ratios of the bearing capacity for the Ston accelerogram were $\mathrm{S} 1: \mathrm{S} 3: \mathrm{S} 6=1: 1.42: 1.71$ and $\mathrm{S} 1 \mathrm{~m}$ : $\mathrm{S} 3 \mathrm{~m}: \mathrm{S} 6 \mathrm{~m}=1: 1.16: 1.16$.

The abovementioned relationships are related to the fact that increasing the number of blocks in a column reduces its stiffness and generates earthquake forces but also decreases the column resistance. The artificial accelerogram is characterized by long-lasting action with high spectral velocities and displacements for longer $T_{1}$, that is, the great earthquake energy. This is considered the cause of decreasing the column's bearing capacity by increasing the number of blocks in it, that is, by decreasing its stiffness.

The Petrovac accelerogram has a shorter duration than the artificial accelerogram with lower spectral velocities and displacements for soft structures. The Ston accelerogram has a short impact action with the lowest spectral velocities and displacements, that is, with the lowest earthquake energy. The abovementioned is the reason why for the Petrovac and Ston accelerograms, an increase in the number of blocks in a column resulted in a greater bearing capacity.
We hope that the obtained experimental database can be useful for the validation of numerical models for the dynamic analysis of multidrum columns.

Although the aforementioned conclusions are based on the experimental study of small-scale models, such an approach may be accompanied with a number of problems and dilemmas. However, it is believed that this experimental approach can reliably be applied to similar full-scale columns because only the relative effect of a single parameter was considered (the number of blocks in a column), while all other influential parameters were kept equal in all the tests.

Further detailed and more comprehensive research of the subject matter is needed to produce more reliable conclusions. The effect of the drum height on the behaviour of multidrum columns exposed to static forces was performed by Buzov et al. [15].

\section{Data Availability}

All data underlying the findings of the study are presented in this paper.

\section{Conflicts of Interest}

The authors declare that there are no conflicts of interest regarding the publication of this paper.

\section{References}

[1] V. Sarhosis, P. Asteris, T. Wang, and W. Hu, "On the stability of colonnade structural systems under static and dynamic loading conditions," Bulletin Earthquake Engineering, vol. 14, no. 4, pp. 1131-1152, 2016.

[2] L. Papaloizou and P. Komodromos, "Planar investigation of the seismic response of ancient columns and colonnades with epistyles using a custom-made software," Soil Dynamics and Earthquake Engineering, vol. 29, no. 11-12, pp. 1437-1454, 2009.

[3] P. Komodromos, L. Papaloizou, and P. Polycarpou, "Simulation of the response of ancient columns under harmonic and earthquake excitations," Engineering Structures, vol. 30, no. 8, pp. 2154-2164, 2008.

[4] D. Konstantinidis and N. Makris, "Seismic response analysis of multidrum classical column," Earthquake Engineering and Structural Dynamics, vol. 34, no. 10, pp. 1243-1270, 2005.

[5] I. Psycharis, J. Lemos, D. Papastamatiou, C. Zambas, and C. Papantonopoulos, "Numerical study of the seismic behavior of a part of the Parthenon Pronaos," Earthquake Engineering and Structural Dynamics, vol. 32, no. 13, pp. 2063-2084, 2003.

[6] C. Papantonopoulos, I. N. Psycharis, D. Y. Papastamatiou, J. V. Lemos, and H. Mouzakis, "Numerical prediction of the earthquake response of classical columns using the distinct element method," Earthquake Engineering and Structural Dynamics, vol. 31, no. 9, pp. 1699-1717, 2002.

[7] V. Sarhosis, P. G. Asteris, A. Mohebkhah, J. Xiao, and T. Wang, "Three dimensional modelling of ancient colonnade structural systems subjected to harmonic and seismic loading," Structural Engineering and Mechanics, vol. 60, no. 4, pp. 633-653, 2016. 
[8] P. G. Asteris, V. Sarhosis, A. Mohebkhah et al., "Numerical modeling of historic masonry structures," in Handbook of Research on Seismic Assessment and Rehabilitation of Historic Structures, Chapter 7, G. Panagiotis Asteris and V. Plevris, pp. 213-256, IGI Global, Hershey, PA, USA, 2015.

[9] V. A. Drosos and I. Anastasopoulos, "Shaking table testing of multi-drum columns and portals," Earthquake Engineering and Structural Dynamics, vol. 43, no. 11, pp. 1703-1723, 2014.

[10] V. A. Drosos and I. Anastasopoulos, "Experimental investigation of the seismic response of classical temple columns," Bulletin Earthquake Engineering, vol. 13, no. 1, pp. 299-310, 2015.

[11] H. P. Mouzakis, I. N. Psycharis, D. Y. Papastamatiou et al., "Experimental investigation of the earthquake response of a model of a marble classical column," Earthquake Engineering AND Structural Dynamics, vol. 31, no. 9, pp. 16811698, 2002.

[12] L. Krstevska, V. Mihailov, E. Boschi, and A. Rovelli, "Experimental dynamic testing of prototype and model of the Antonina column in Roma," in Proceedings of the 11th WCEE, Paper No. 546, Acapulco, GRO, Mexico, 1996.

[13] A. Buzov, J. Radnić, N. Grgić, and G. Baloević, "Effect of the joint type on the bearing capacity of a multi-drum column under static load," International Journal of Architectural Heritage, vol. 12, no. 1, pp. 137-152, 2018.

[14] European Committee for Standardization (CEN) EN 12390-3, Testing Hardened Concrete-Part 3: Compressive Strength of Test Specimens, 2009.

[15] A. Buzov, J. Radnić, N. Grgić, and G. Baloević, "Effect of the drum height on the bearing capacity of composite multi-drum column under static load," Composites Part B: Engineering, vol. 148, pp. 243-251, 2018.

[16] European Committee for Standardization (CEN) EN 1998-1, Eurocode 8: Design of Structures for Earthquake ResistancePart 1: General Rules, Seismic Actions and Rules for Buildings, 2004.

[17] N. Ambraseys, P. Smit, R. Sigbjörnsson, P. Suhadolc, and B. Margaris, Internet-Site for European Strong-Motion Data, EVR1-CT-1999-40008, European Commission, DirectorateGeneral XII, Environmental and Climate Programme, Bruxelles, Belgium, 2001, http://www.isesd.cv.ic.ac.uk. 


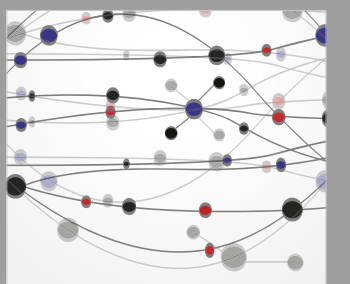

The Scientific World Journal
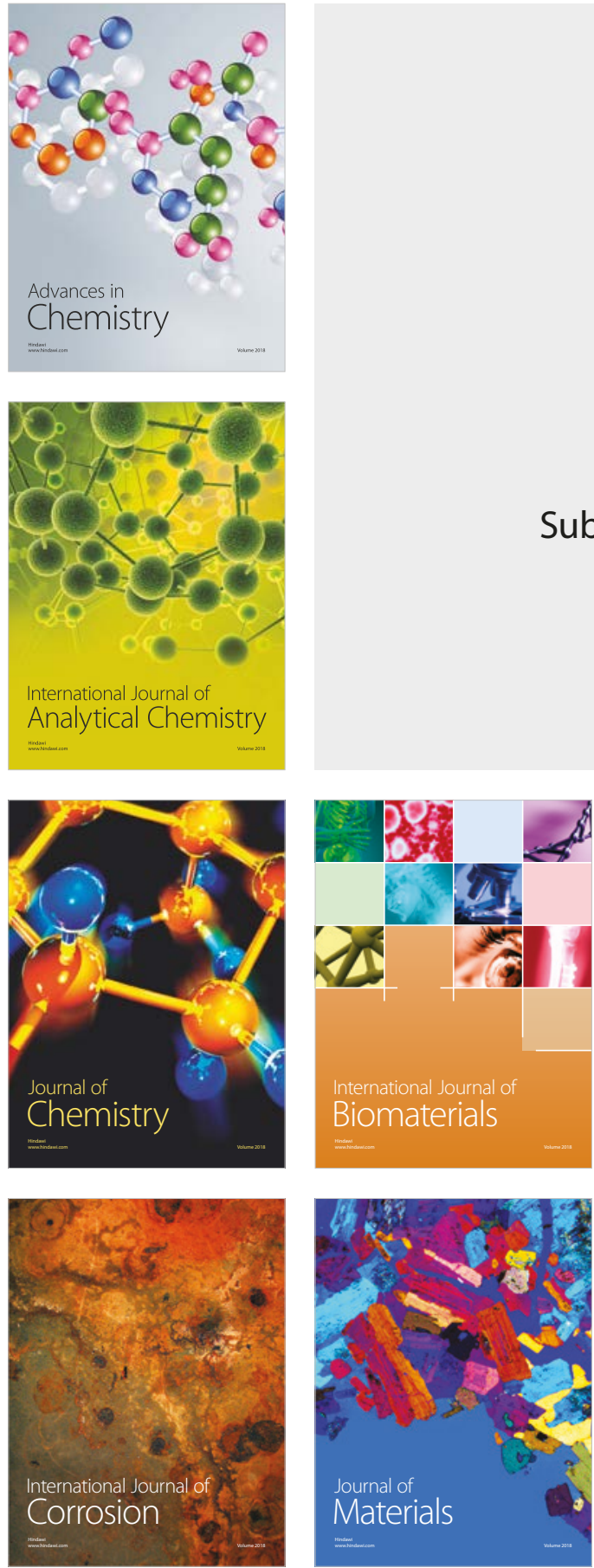

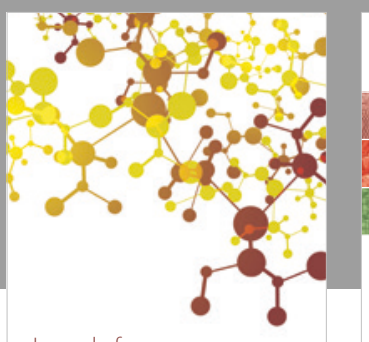

Journal of

Applied Chemistry
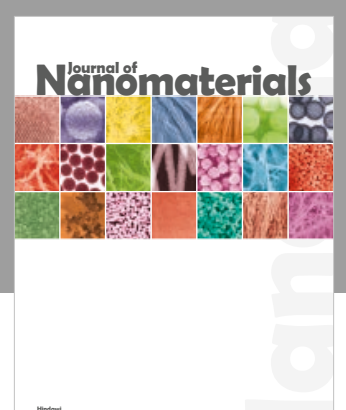

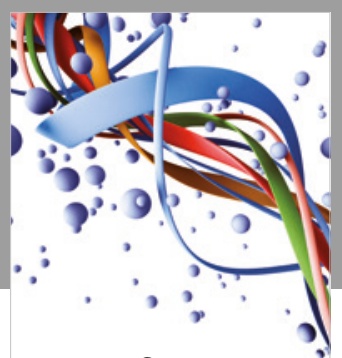

Scientifica

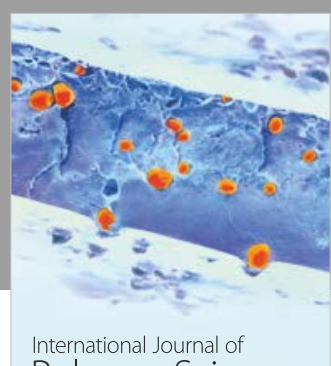

Polymer Science

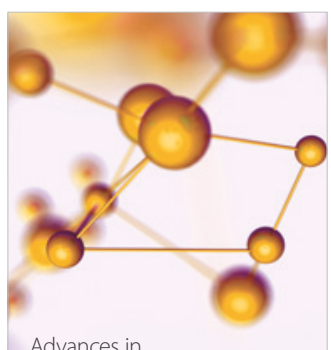

Physical Chemistry
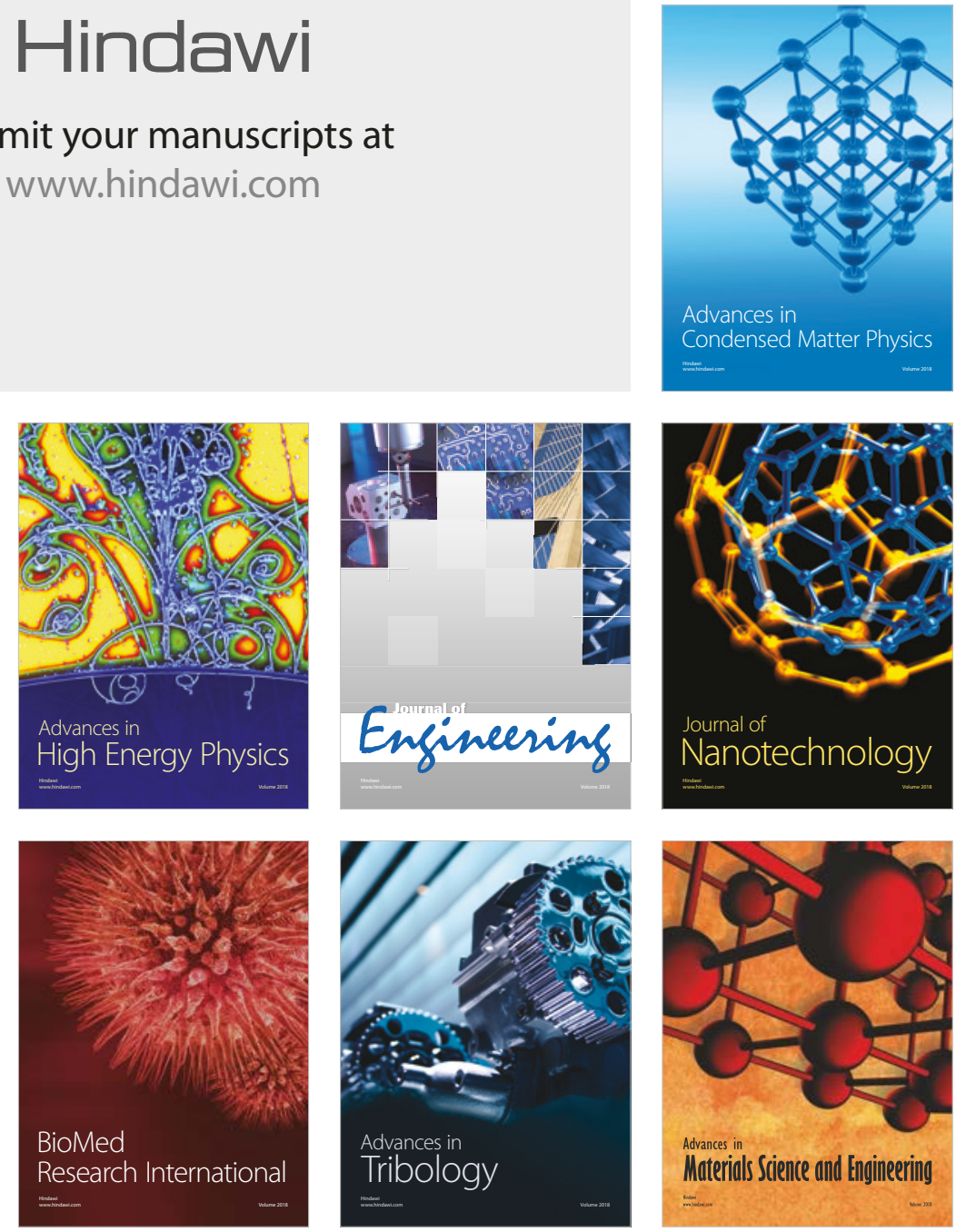